\title{
Olive pollen profilin (Ole e 2 allergen) co-localizes with highly active areas of the actin cytoskeleton and is released to the culture medium during in vitro pollen germination
}

\author{
S. MORALES, J.C. JIMÉNEZ-LÓPEZ, A.J. CASTRO, \\ M.I. RODRÍGUEZ-GARCÍA \& J.D. ALCHÉ \\ Department of Biochemistry, Cell and Molecular Biology of Plants, Estación Experimental del Zaidin. \\ CSIC, Profesor Albareda, 1, 18008 Granada, Spain
}

Key words. Actin, allergen, cytoskeleton, Ole e 2, olive tree, pollen tube, profilin.

\section{Summary}

Pollen allergens offer a dual perspective of study: some of them are considered key proteins for pollen physiology, but they are also able to trigger allergy symptoms in susceptible humans after coming in contact with their tissues. Profilin (Ole e 2 allergen) has been characterized, to some extent, as one of the major allergens from Olea europaea L. pollen, a highly allergenic species in the Mediterranean countries. In order to obtain clues regarding the biological role of this protein, we have analyzed both its cellular localization and the organization of actin throughout pollen hydration and early pollen tube germination. The localization of the cited proteins was visualized by confocal laser scanning microscopy immunofluorescence using different antibodies. Upon pollen hydration and pollen germination, a massive presence of profilin was detected close to the site of pollen tube emergence, forming a ring-like structure around the 'effective' apertural region. Profilin was also detected in the pollen exine of the germinating pollen grains and in the germination medium. After using a permeabilization-enhanced protocol for immunolocalization, profilin was also localized in the cytoplasm of the pollen tube, particularly at both the proximal and apical ends. Noticeable accumulations of actin were observed in the cytoplasm of the pollen tube; particularly, in both the apical region and the area immediately close to the aperture. Actin filaments were not observed, probably due to the need of further enhanced fixation procedures. The ultrastructural localization of profilin showed the presence of the protein in the cytoplasm of both the mature pollen grain and the pollen tube.

Correspondence to: M.I. Rodríguez-García. Tel: +34-958181600; fax: +34958129600; e-mail: mariaisabel.rodriguez@eez.csic.es
The results shown here could be interpreted as signs of a massive dissociation of the actin-profilin complexes, mobilization of actin monomers, and therefore, an intense activity of the actin cytoskeleton. The extensive release of allergenic proteins from the pollen grain into the surrounding aqueous media, as described here for profilin, may help us to understand the mechanisms by which these allergens might come in contact with the human mucosa, therefore triggering the symptoms of allergy.

\section{Introduction}

During sexual reproduction in flowering plants, the male gametes are transported to the ovules by way of the growing pollen tubes (Bedinger \& Edgerton, 1989; Mascarenhas, 1993; Taylor \& Hepler, 1997). The process of pollen tube elongation is typically very rapid (Bedinger et al., 1994; Cárdenas et al., 2005), and as in many other tip-growing cells in which the cell directs most of its resources to a single site, there is a strong dependence of the presence of an intact and dynamic actin cytoskeleton (see Geitmann \& Emons, 2000 for review). Different actin-binding proteins (ABPs) have been described to spatially and temporally regulate the changes in the organization and mechanical properties of the actin cytoskeleton in response to cell signalling. They include tropomyosin, profilin, cofilin and other members of the actin-depolymerizing factor (ADF) family, among others (Staiger, 2000; Chen et al., 2002; dos Remedios et al., 2003; Ren \& Xiang, 2007). ABPs have a significant influence in the behaviour of the cellular cytoskeleton (Gibbon \& Staiger, 2000; Staiger, 2000), and profilin is one of the most important ABPs (Staiger \& Blanchoin, 2006). They have been described as ubiquitous, multifunctional and very soluble proteins. They can limit actin polymerization by sequestering 
actin monomers, hence suppressing their addition to the microfilament pointed ends when the barbed ends are capped (Goldschmidt-Clermont \& Janmey, 1991; Carlier \& Pantaloni, 1994; Perelroizen et al. 1996; Huang et al., 2003). Profilins can have either a positive or a negative effect on actin polymerization (Theriot \& Mitchison, 1993), promoting or inhibiting actin filament assembly. This effect depends on many factors, including the profilin/G-actin ratio, the ionic medium condition, and the presence and activity of other ABPs (Pantaloni \& Carlier, 1993; Staiger et al., 1997; Gibbon \& Staiger, 2000). Several characteristics of the interaction between actin and profilin have been demonstrated in vitro (Valenta et al., 1993; Staiger et al., 1994; Vidali \& Hepler, 1997) and also by microinjection experiments (Cao et al., 1992; Staiger et al., 1994; Gibbon et al., 1997, 1998; Holzinger et al. 1997; Valster et al., 1997).

Profilin also interacts with the protein sequences that are able to shape a type II poly-l-proline helix and with polyphosphoinositides (Machesky \& Pollard, 1993; Schlüter et al., 1997). Therefore, profilin may mediate a link among the signalling pathways to control the cytoskeletal rearrangements in response to stimuli (Deeks et al., 2002). They also take part in the vesicle trafficking between the endoplasmic reticulum (ER) and the transGolgi, endocytosis/exocytosis cycles, macropinocytosis and phagocytosis (Haugwitz et al., 1994; Lee et al., 2000).

Plant profilins have been shown to be highly cross-reactive allergens within a broad range of species and plant tissues. Pollen profilins bind to IgE antibodies of allergic patients in a variable proportion, which may reach a $20 \%$ of all pollenallergic patients, thus triggering the symptoms of type I allergy (Valenta et al., 1991). Ole e 2 is one of the 10 allergens (referred to as Ole e 1-Ole e 10) isolated and characterized from the olive pollen up to this date. The most prevalent olive allergen is Ole e 1 , which affects more than $70 \%$ of patients hypersensitive to the olive pollen, but others, such as Ole e 2 , Ole e 8 , and Ole e 9, have also been demonstrated to be major allergens (Rodríguez et al., 2002).

The olive pollen profilin (Ole e 2 allergen) has been characterized, sequenced and expressed in Escherichia coli, showing an $86 \%$ and a $73 \%$ homology to birch and grass profilins, respectively (Ledesma et al., 1998; Martínez et al., 2002). The protein displays three major isoforms in olive pollen, with molecular weights in the range of 15-18 kDa and a high degree of polymorphism in both its nucleotide and amino acid sequences. In spite of these differences in the protein sequence among the profilins, three-dimensional (3D) models for these proteins are very conserved even throughout kingdoms (Schutt et al., 1993; Vinson et al., 1993; Federov et al., 1994; 1997). Although profilin has been localized in different plant cells and tissues, including the microspores, pollen grains and pollen tubes (Grote et al., 1995; Vidali \& Heppler, 1997; von Witsch et al., 1998; Valster et al., 2003), no clear picture has yet been established about the precise location of profilin in the pollen tubes (Geitmann \& Emons, 2000). In the present work, we describe the localization of profilin and actin in the mature olive pollen grain throughout the early stages of pollen germination.

\section{Materials and methods}

\section{Pollen material}

Mature pollen grains taken from selected Olea europaea L. trees (cv. Picual) in Granada (Spain) were collected during the anthesis period using large paper bags by vigorously shaking the inflorescences. Pollen was sequentially sieved through a mesh (pore sizes of $15^{\circ}$ and $50 \mu \mathrm{M}$ ) in order to separate the grains from the debris. The pollen grains were then frozen in liquid nitrogen and stored at $-80^{\circ} \mathrm{C}$.

\section{In vitro pollen germination}

Pre-hydration of the stored pollen was performed by incubation in a humid chamber at $30^{\circ} \mathrm{C}$ for $30 \mathrm{~min}$. The grains $(0.02 \mathrm{~g} /$ plate $)$ were then transferred to Petri dishes containing $10 \mathrm{~mL}$ of the germination medium $[10 \%(\mathrm{w} / \mathrm{v})$ sucrose, $0.03 \%$ $(\mathrm{w} / \mathrm{v}) \mathrm{Ca}\left(\mathrm{NO}_{3}\right)_{2}, 0.01 \%(\mathrm{w} / \mathrm{v}) \mathrm{KNO}_{3}, 0.02 \%(\mathrm{w} / \mathrm{v}) \mathrm{MgSO}_{4}$ and $0.03 \%(\mathrm{w} / \mathrm{v})$ boric acid], as described by M'rani-Alaoui (2000). The Petri dishes were maintained at $25^{\circ} \mathrm{C}$ in the dark, and the pollen samples were taken at $1,2,3$, and $5 \mathrm{~h}$ of monitoring of the pollen tube growth by light microscopy. Finally, the pollen was pelleted by centrifugation $(1000 \times \mathbf{g}$ for $20 \mathrm{~s})$.

\section{Protein extraction and immunoblot analysis}

Mature pollen samples were re-suspended in an extraction buffer [40 mu Tris-HCl (pH 8.8), 2\% (v/v) Triton X-100, 1 $\mathrm{mg} / \mathrm{mL}$ ascorbic acid, $10 \mu \mathrm{g} / \mu \mathrm{L}$ protease inhibitor cocktail (Sigma, Madrid, Spain)] to a proportion of $10 \mathrm{~mL}$ solution per gram of fresh tissue and then incubated at $4^{\circ} \mathrm{C}$ for $4 \mathrm{~h}$ with vigorous shaking. After centrifugation at $13000 \times \mathbf{g}$ for $30 \mathrm{~min}$ at $4^{\circ} \mathrm{C}$, the supernatants were removed, dispensed into aliquots and stored at $-20^{\circ} \mathrm{C}$. The protein concentration in each sample was measured following the Bradford (1976) method, using the Bio-Rad reagent and bovine serum albumin (BSA) (Bio-Rad, Barcelona, Spain) as standard. In total, $30 \mu \mathrm{g}$ of protein per lane was loaded into a $12 \%$ sodium dodecyl sulfate (SDS)-polyacrylamide gel (PAGE), as described by Laemmli (1970). The proteins were separated using a MaxiProtean II xi Cell system (Bio-Rad). Gels were stained with Coomassie blue, or transferred onto polyvinylidenedifluoride (PVDF) membranes at $25 \mathrm{~V}$ for $30 \mathrm{~min}$ in a semi-dry transfer cell (Bio-Rad). For immunodetection, blots were incubated for $4 \mathrm{~h}$ at $25^{\circ} \mathrm{C}$ with a blocking solution containing $0.1 \%$ $(\mathrm{v} / \mathrm{v})$ Tween 20 and 10\% (w/v) dried skimmed milk in Trisbuffered saline (TBS). The membranes were then probed with the following antibodies: 
Anti-Ole e 2 polyclonal serum diluted $1 / 25000$ in the same blocking solution, overnight at $4^{\circ} \mathrm{C}$. The serum was produced by immunization of rabbits with a keyhole limpet hemocyanin (KLH)-linked synthetic peptide (' $N$ 'AQSATFPQFKPEEM-KLH) designed on the basis of the olive profilin-predicted sequences (Jiménez-López et al., unpublished data), according to the protocols recommended by the manufacturer (Genosphere, Paris, France). The membranes were washed three times for $10 \mathrm{~min}$ in TBS containing $0.1 \%$ (v/v) Tween (TBST) and incubated with a goat anti-rabbit IgG Alexa 633-conjugated secondary antibody (Molecular Probes, Invitrogen, Paisley, UK), diluted 1/10 000 in TBS for $2 \mathrm{~h}$ at room temperature (RT) in the dark. The final rinses were performed using TBS.

Anti-actin monoclonal antibody, clone C4 (Sigma), diluted $1 / 10000$ as above. Further treatment of blots was as described above, although using a goat anti-mouse IgG Alexa 488-conjugated (Molecular Probes) diluted 1/10 000 as the secondary antibody.

The detection of reactive bands was carried out using Pharos System (Bio-Rad) with the Ar (488 nm) laser and the 635$\mathrm{nm}$ laser diode. The bands analyses were performed using the QuanTity One 4.6.2 (Bio-Rad) software.

\section{Whole-cell immunostaining of profilin}

In vitro germinated pollen samples were transferred to $1.5 \mathrm{~mL}$ disposable plastic tubes and then fixed at $4^{\circ} \mathrm{C}$ for $3 \mathrm{~h}$ in a solution containing $4 \%(\mathrm{w} / \mathrm{v})$ paraformaldehyde (PF) and 1\% glutaraldehyde (GA) in buffer 1 [50 mm 1,4-piperazinediethane sulfonic acid (PIPES), $5 \mathrm{~mm}$ ethylene glycol-bis(2-aminoethylether)-N,N, $\mathrm{N}^{\prime}, \mathrm{N}^{\prime}$-tetraacetic acid (EGTA), $5 \mathrm{~mm} \mathrm{MgSO}_{4}$ (pH 7.0)]. At the end of each step described hereafter, the pollen grains were allowed to settle by gravity and then the corresponding solution replaced by the next. The samples were subsequently incubated at $4^{\circ} \mathrm{C}$ in the following solutions, using gentle agitation: $0.1 \%$ Triton X-100 in buffer 1 (washing buffer), three changes of 10 min each; permeation with cold $\left(-20^{\circ} \mathrm{C}\right)$ acetone $5 \mathrm{~min}$; washing buffer, three changes of $10 \mathrm{~min}$ each; $2 \%$ BSA in buffer 1 (blocking solution) $20 \mathrm{~min}$; washing solution, three changes of $10 \mathrm{~min}$ each. The samples were incubated overnight at $4^{\circ} \mathrm{C}$ with the anti-Ole e 2 polyclonal serum diluted 1/200 in blocking solution. After washing, the samples were incubated with a goat anti-rabbit IgG Cy3-conjugated secondary antibody (Sigma), diluted 1/1000 in the blocking solution for $2 \mathrm{~h}$ in the dark at RT. The final rinses were performed using the washing solution. Finally, the samples were re-suspended in a Citifluor/glycerol/phosphate-buffered saline (PBS) anti-fade solution (Sigma) and observed with a Nikon $\mathrm{C} 1$ confocal laser scanning microscope equipped with an $\mathrm{He}-\mathrm{Ne}$ (543 nm) laser and multi-band filters set (Nikon, Tokyo, Japan). Z-series images were collected and processed with the software EZ-C1 Gold version 2.10 build 240 (Nikon).
Whole-cell immunostaining of profilin and actin (extended protocol)

An alternative protocol was used based on the procedures described by Friml et al. (2003) and Szechynska-Hebda et al., (2006) with some modifications. In vitro germinated pollen was collected and immediately fixed by adding an equal volume of $4 \% \mathrm{PF}$ in buffer 1 . After $5 \mathrm{~min}$, the pollen was collected by centrifugation and then further fixed in $4 \% \mathrm{PF}$ in buffer 1 for $5 \mathrm{~min}$ at RT. The samples were rinsed with the washing buffer $(3 \times 10 \mathrm{~min})$ and then equilibrated in buffer 2 [50 mм PIPES, 5 mм EGTA, $5 \mathrm{~mm} \mathrm{MgSO}_{4}(\mathrm{pH} 4.5$ ), $0.1 \%$ Triton X-100] $(2 \times 10 \mathrm{~min})$. The cell walls were digested with $2 \%(\mathrm{w} / \mathrm{v})$ driselase, $6 \%(\mathrm{w} / \mathrm{v})$ pectinase and $4 \%(\mathrm{w} / \mathrm{v})$ cellulase in buffer 2 for $1 \mathrm{~h}$ at $50^{\circ} \mathrm{C}$, washed again with the washing buffer $(5 \times 10 \mathrm{~min})$ and then incubated in $10 \%$ dimethyl sulfoxide (DMSO), 3\% NP-40 in buffer 1 for 50 min at RT. After further washing $(3 \times 10 \mathrm{~min})$, the pollen grains were post-fixed with $4 \%$ PF for $10 \mathrm{~min}$, incubated in the blocking solution for $30 \mathrm{~min}$ at RT, washed in buffer $1(3 \times 10 \mathrm{~min})$ and incubated with the following antibodies:

Anti-Ole e 2 polyclonal serum diluted 1/200 in the blocking solution, overnight at $4^{\circ} \mathrm{C}$. After washing, the samples were incubated with the goat anti-rabbit IgG Alexa 633conjugated secondary antibody (Molecular Probes), diluted $1 / 100$ in the blocking solution for $3 \mathrm{~h}$ at RT in the dark. The final steps were as described for the standard protocol. The observations were carried out using the $\mathrm{He}-\mathrm{Ne}(633 \mathrm{~nm})$ laser (Nikon).

Anti-actin monoclonal antibody, clone C4 (Sigma), diluted 1:5 in the blocking solution, overnight at $4^{\circ} \mathrm{C}$. After washing, the samples were incubated with a goat anti-mouse IgG Alexa 488-conjugated secondary antibody (Molecular Probes), diluted $1 / 100$ in the blocking solution for $3 \mathrm{~h}$ at RT in the dark. The final steps were as described for Ole e 2 antiserum. The observation and image capture were performed by exciting with an $\mathrm{Ar}$ (488 nm) laser (Nikon).

\section{Transmission Electron Microscope (TEM) immunolocalization of profilin}

The germinated pollen grains were fixed for $2 \mathrm{~h}$ at $4^{\circ} \mathrm{C}$ in $0.1 \%(\mathrm{v} / \mathrm{v})$ glutaraldehyde (GA) and $4 \%(\mathrm{w} / \mathrm{v})$ PF in buffer 1 . The samples were dehydrated in an ethanol series and embedded in Unicryl resin (BBInternational, Cardiff, UK) following a progressive lowering of temperature (PLT) schedule, as described by Alché et al. (1999). Ultra-thin sections $(80 \mathrm{~nm})$ were cut with an ultramicrotome (ŔeichertJung, Vienna, Austria) and transferred on to formvar-coated 300-mesh nickel grids. Blocking of non-specific binding sites was carried out by incubation of sections for $2 \mathrm{~h}$ in a solution containing 5\% (w/v) BSA in buffer 1 . The blocking was followed by washing in buffer 1 for $10 \mathrm{~min}$ and incubation at RT for $2.5 \mathrm{~h}$ with the anti-Ole e 2 antibody described above, diluted $1 / 50$ in the blocking solution. After washing 
several times with buffer 1 , the grids were treated for 2 $\mathrm{h}$ with a goat anti-rabbit IgG secondary antibody coupled to 15-nm gold particles (BBInternational) diluted 1/100 in the blocking solution. Finally, they were washed in buffer 1 $(5 \times 5 \mathrm{~min})$, rinsed in double-distilled water $(3 \times 5 \mathrm{~min})$ and then stained for 15 min with a solution of $5 \%(\mathrm{w} / \mathrm{v})$ uranyl acetate in the dark. The observations were carried out with a JEM-1011 (JEOL, Tokyo, Japan) TEM. The treatment of control sections was the same, although incubation with the primary antibody was omitted.

\section{Results}

\section{SDS-PAGE Western blot}

Crude extracts of mature pollen grains showed the protein pattern displayed in Fig. 1 after SDS-PAGE and Coomassie staining. A conspicuous band of approximately $18 \mathrm{kDa}$ corresponded to the olive pollen major allergen, Ole e 1 (Fig. 1; Lane 1). When parallel sets of samples were transferred

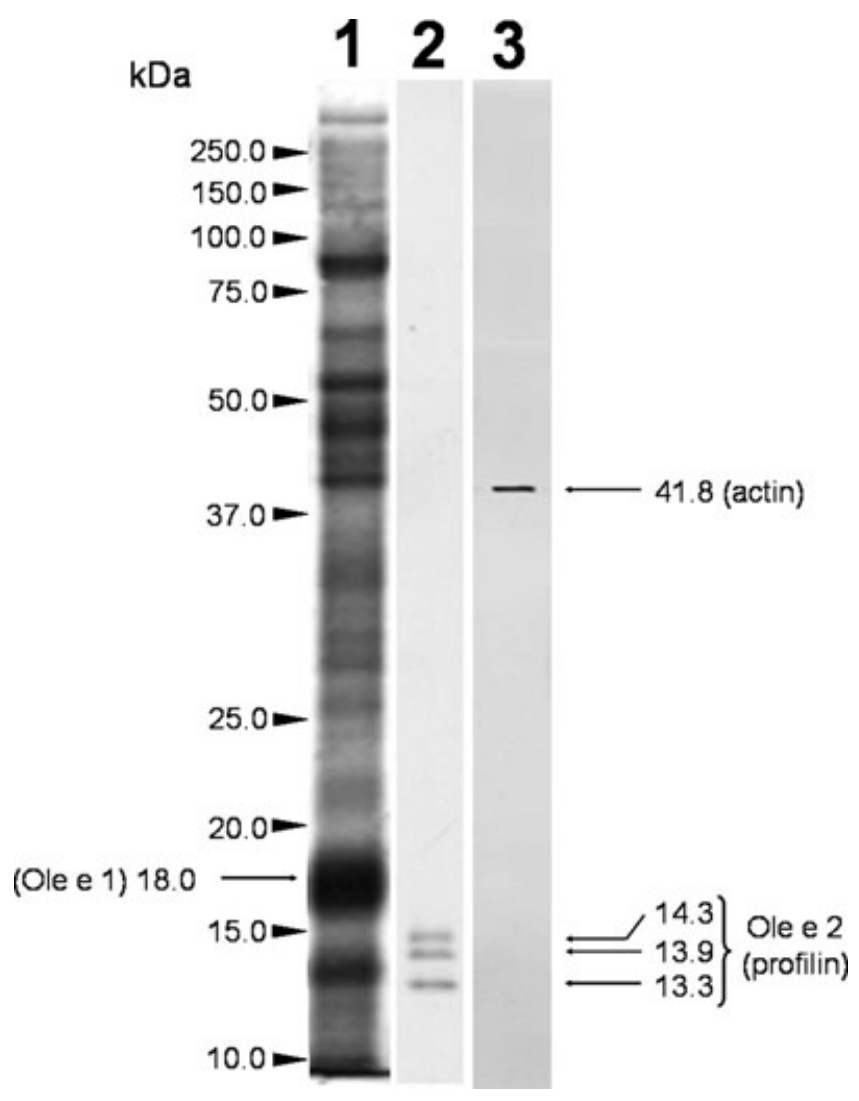

Fig. 1. Western blotting identification of the reactivity of anti-profilin serum and anti-actin antibody, respectively, to olive pollen crude protein extracts. Lane 1. Coomassie blue-stained gel. Lane 2. Immunoblot showing three cross-reactive profilin isoforms of 13.3, 13.9 and $14.3 \mathrm{kDa}$ apparent molecular masses. Lane 3. Immunoblot showing a band of $41.5 \mathrm{kDa}$ recognized by the anti-actin antibody. In total, $30 \mu \mathrm{g}$ of total protein was loaded per lane. on to membranes and probed with an anti-serum to olive profilin (Ole e 2 allergen), three reactive bands were detected, with apparent molecular masses of 13.3, 13.9 and $14.3 \mathrm{kDa}$ (Fig. 1; Lane 2). The same extracts showed a single reactive band of $41.8 \mathrm{kDa}$ apparent molecular mass after being probed with a monoclonal antibody to actin (Fig. 1; Lane 3).

\section{CLSM immunolocalization of profilin}

To determine the intracellular distribution of profilin, a series of immunolocalization studies were performed. Initial localization was performed by chemically fixing the cells, followed by slight membrane permeabilization and immunostaining using a Cy3-labelled secondary antibody (Fig. 2). Using this procedure, we found that the antiprofilin antibody bound to the allergen Ole e 2 localized to a conspicuous ring-like structure surrounding the aperture region from which the emergence of the pollen tube took place, and not to the other two aperture regions of the pollen grain (Fig. 2A and $\mathrm{A}^{\prime}$ ). Additional labelling occurred at the pollen wall and in the germination medium. The pollen grains failing to either hydrate or produce a pollen tube showed no profilin signal on their surface, or the ring-like labelling around any of their apertures (Fig. 2A and $\mathrm{A}^{\prime}$ ). No fluorescent labelling was observed either inside the pollen grain or inside the pollen tube. The negative controls did not show any labelling (Fig. 2B and $\mathrm{B}^{\prime}$ ).

In order to improve the penetration of reagents (mainly antibodies) throughout the whole-mount protocol, an extended procedure was used, which included an additional step of digestion using cell wall-loosening enzymes and improved permeabilization with a solution of DMSO and NP-40 detergent. Using this extended protocol, the profilin labelling occurred in the three apertural regions of the pollen grain at early stages of pollen in vitro germination (1-2 h), (Fig. $3 \mathrm{~A}$ and $\mathrm{B}, \mathrm{A}^{\prime}$ and $\mathrm{B}^{\prime}$ ). The labelling did not always occur equally in all apertures. The signal frequently displayed a higher intensity in one out of the three apertures. This was particularly evident when projections of the seriate optical sections covering the whole pollen grain structure were analyzed instead of single sections (Fig. 3A and B). After 3-5 $\mathrm{h}$ of in vitro pollen culture, the pollen tubes had sufficiently emerged from the pollen grain to permit staining. Profilin labelling was observed in the apical region of the pollen tube and in the cytoplasm region close to the aperture. No significant labelling was observed in association with the nuclei within the pollen tube (Fig. 3C and $\mathrm{C}^{\prime}$ ).

No labelling within the pollen grain itself was observed in any of the stages studied. After using this extended procedure, a significant diminution in the signals present in the pollen exine and the culture medium (particularly in the later) was detected. The ring-like labelling surrounding the effective aperture was also substantially reduced. The intensity of labelling in these outer structures was dependent 


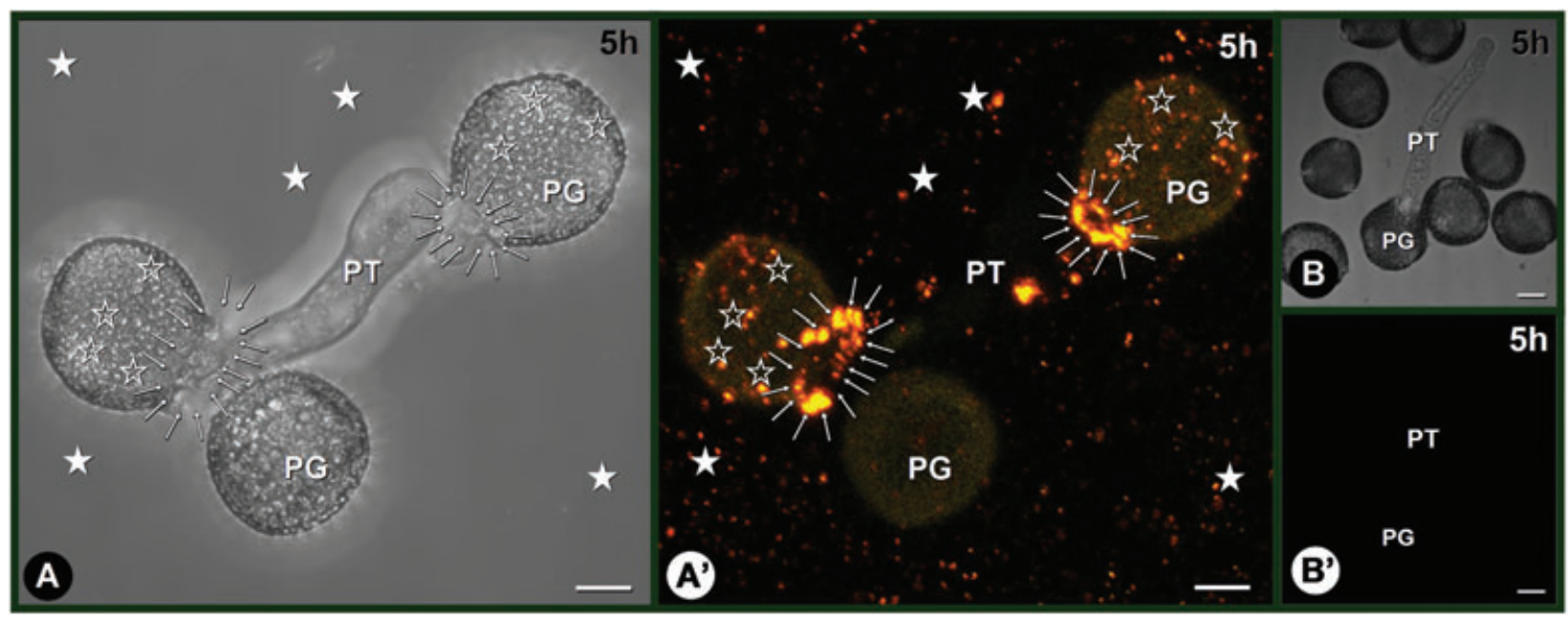

Fig. 2. CLSM immunolocalization of profilin on whole-mount preparations of olive pollen cultured in vitro. (A, A') Profilin labelling is prominently observed around the effective aperture regions (those from which the pollen tube emergence finally takes place), forming ring-like structures (large thin arrows). Intense fluorescence is also observed in the pollen exine (empty stars) of the germinating pollen grains and in the culture medium (filled stars). No fluorescence is observed in pollen tubes. (B, B') Negative controls display no significant fluorescence over the background. (A, B) CLSM (projection of 30 optical sections) and transmitted light. (A', B') CLSM (projection of 30 optical sections) only. Abbreviations: PG, pollen grain; PT, pollen tube. Bars: $10 \mu \mathrm{m}$.

on the intensity and extension of the washing steps included in the protocol (results not shown). The negative controls did not show any significant fluorescence tagging (Fig. 3D and $\mathrm{D}^{\prime}$ ).

\section{CLSM immunolocalization of actin}

Actin was immunolocalized by incubating with a monoclonal antibody to actin throughout the extended procedure

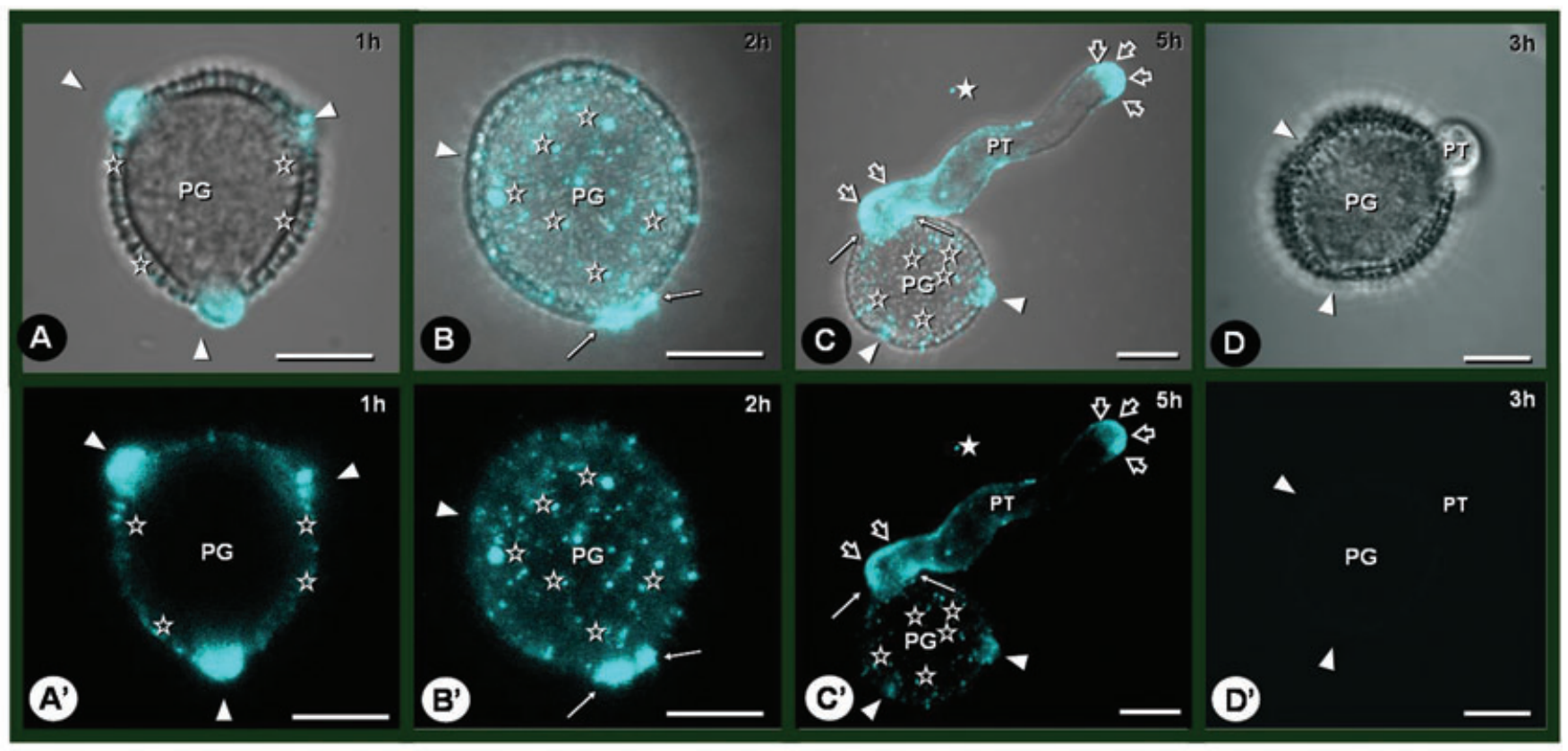

Fig. 3. CLSM immunolocalization of profilin on whole-mount preparations of olive pollen cultured in vitro after using the extended treatment including cell wall digestion. (A-C and A'-C') Profilin labelling at different times after the culture onset ( $1 \mathrm{~h}, 2 \mathrm{~h}$ and $5 \mathrm{~h}$ ) occurs in the apertures (arrowheads), the pollen exine (empty stars) and the surrounding medium (filled stars). The pollen tube shows fluorescence in both the apical and basal areas (empty arrows and long thin arrows, respectively). (D, D') Negative controls display no significant fluorescence over the background. (A-D) CLSM (projection of 30 optical sections, except (A), which is a single section) and transmitted light. (A', B') CLSM (projection of 30 optical sections, except (A), which is a single section) only. Abbreviations: PG, pollen grain; PT, pollen tube. Bars: $10 \mu \mathrm{m}$. 


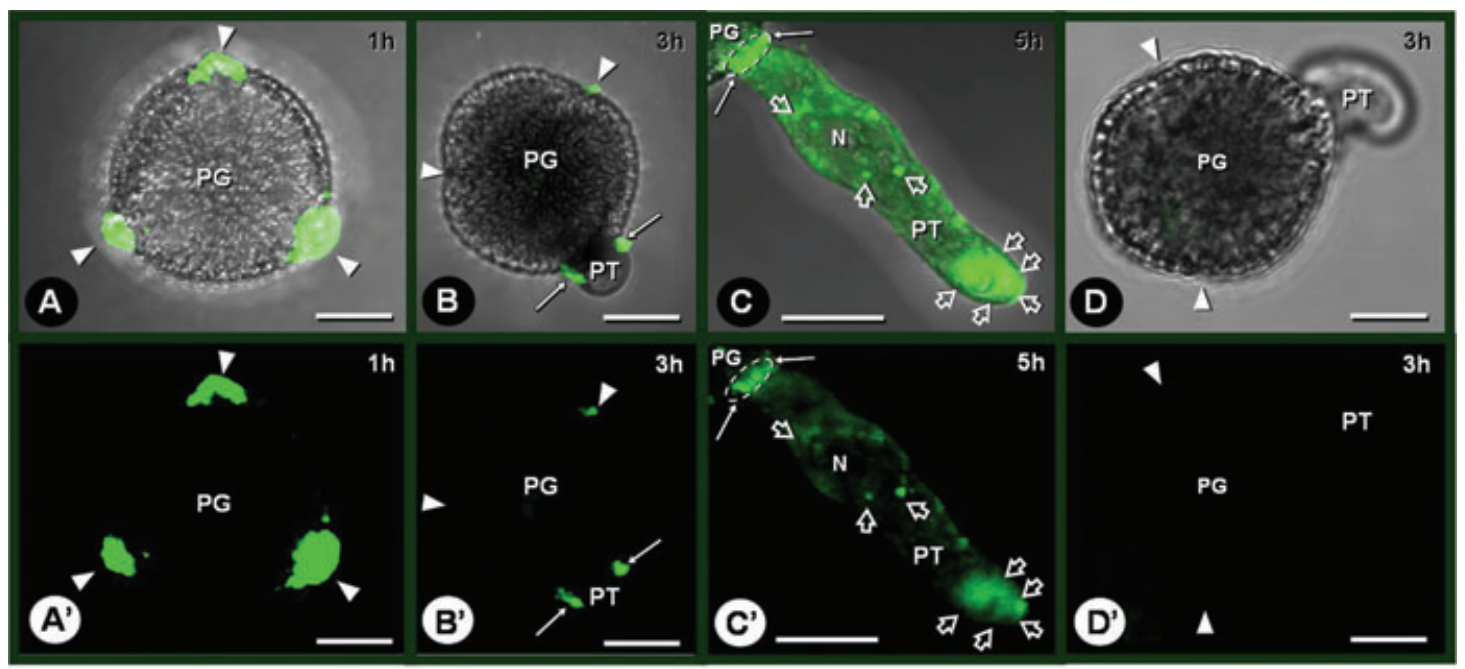

Fig. 4. CLSM immunolocalization of actin on whole-mount preparations of olive pollen cultured in vitro after using the extended treatment including cell wall digestion. (A-C and A'-C') Actin labelling at different times after the culture onset ( $1 \mathrm{~h}, 3 \mathrm{~h}$ and $5 \mathrm{~h}$ ) occurs in the apertures (arrowheads). The pollen tube displays presence of actin in both the apical and basal areas (empty arrows and long thin arrows, respectively). Some fluorescent spots are also visible in the cytoplasm, although no clear individualized filaments are visible. The generative nucleus shows no fluorescence. (D, D') Negative controls display no significant fluorescence over the background. (A-D) CLSM (optical sections, except (C), which is a projection of 30 optical sections) merged with transmitted light. (A', B') CLSM (optical sections except (C), which is a projection of 30 optical sections) only. Abbreviations: N, nucleus; PG, pollen grain; PT, pollen tube. Bars: $10 \mu \mathrm{m}$.

described above. During early stages of the in vitro culture, corresponding to pollen hydration and initial emergence of the pollen tube (1-3 h), the actin was localized in the three apertural regions of the pollen grain (Fig. $4 \mathrm{~A}$ and B, A' and B'). After emergence of the pollen tube, noticeable accumulations of actin were observed in the cytoplasm of the pollen tube, particularly in both the apical region and the area immediately close to the aperture. Some accumulations were also present in close proximity to the generative nucleus. Within the pollen tube, no microfilaments could be discerned, even at higher magnifications (not shown). No labelling was observed in the pollen exine, or within the pollen grain itself (Fig. $4 \mathrm{C}$ and $\mathrm{C}^{\prime}$ ). No fluorescence was detected in the negative controls (Fig. 4D and $\mathrm{D}^{\prime}$ ).

\section{TEM immunolocalization of profilin}

The pollen sections showed a well-preserved ultrastructure, although the relative mild fixation and the absence of osmium post fixation accounted for the scarce contrast observed, particularly in the membranes. No microfilaments or microtubules were distinguished. Immunogold labelling of ultra-thin sections of the olive pollen allowed in this case the observation of profilin location within the pollen grain. The electron micrographs showed gold particles uniformly distributed throughout the cytoplasm of the vegetative cell (Fig. 5A). The membranes and the compartments they delimit (poorly differentiated organelles, vesicles, and vacuoles) were not labelled. Profilin was widely localized in the pollen exine, particularly in the ectexine, and in the material externally adhered to the pollen wall. The intine was practically devoid of gold particles (Fig. 5B). The negative control experiments produced no or very low gold labelling (Fig. 5C).

TEM immunolocalization of profilin during early pollen germination and in pollen tubes showed abundant and homogeneous labelling in the cytoplasm of the pollen tube, as a continuation of the cytoplasm of the vegetative cell (Fig. 6A). No significant numbers of gold particles were detected in the vesicles or organelles of the pollen tube. The pollen tube cell wall was also devoid of gold (Fig. 6B). A relatively large accumulation of gold particles was observed in the aperture region corresponding to pollen tube emergence. In this region, numerous gold particles decorated the thickened regions of the exine that delimit the aperture region (Fig. 6C).

\section{Discussion}

The differences in the localization of profilin between the two procedures described in the present paper for whole-mount immunofluorescence detection can be attributed to differences in the ability of chemicals (and particularly antibodies) to penetrate through the cell walls. This limitation, clearly observed after using the standard protocol, was solved after the application of cell wall-loosening enzymes and an improved permeabilization. The standard procedure allowed, on the other hand, visualization of one of the most characteristic features of the allergenic proteins: their rapid solubilization and release into aqueous media upon pollen hydration and activation. This is a typical characteristic that has been 


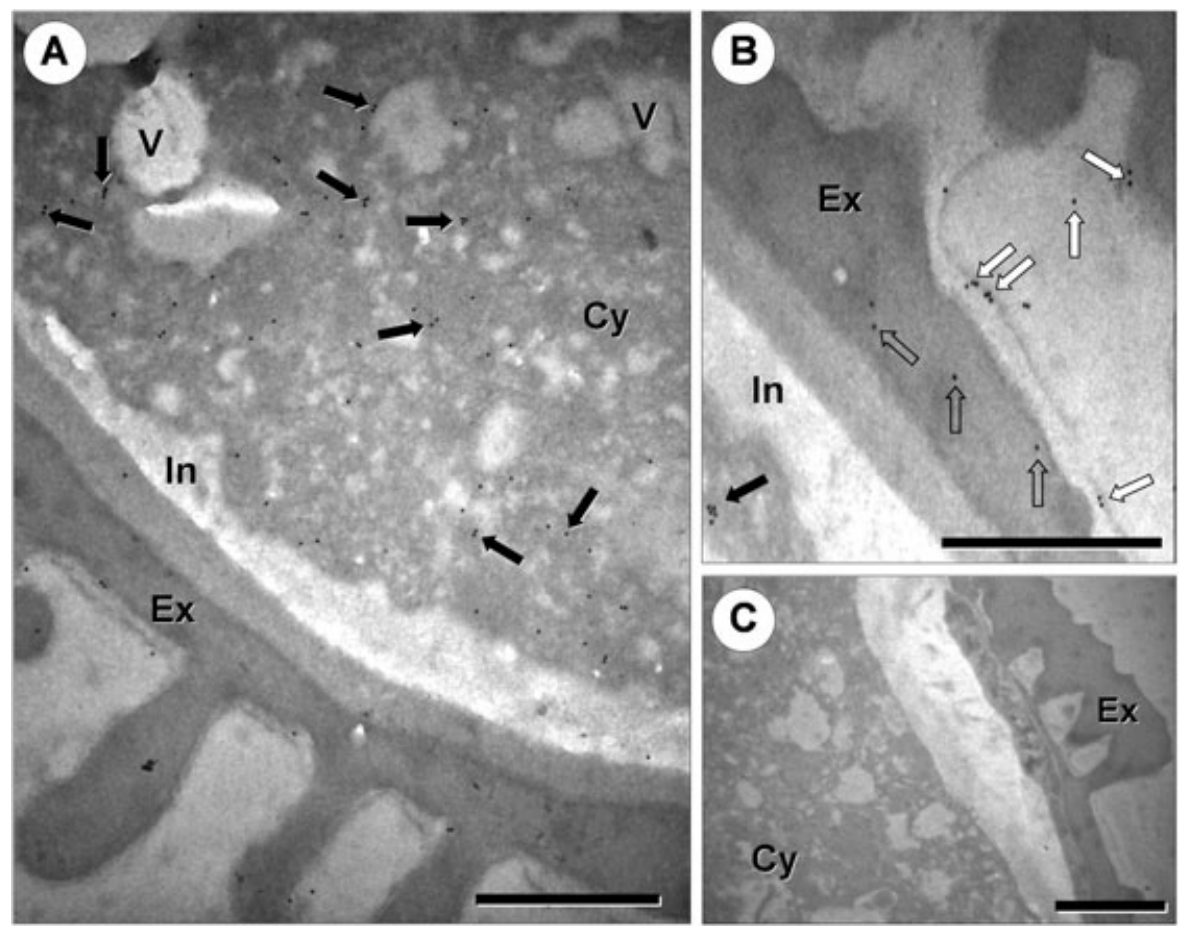

Fig. 5. TEM immunolocalization of profilin on ultra-thin sections of mature pollen grains. (A) Cytoplasm of the vegetative cell showing profilin gold labelling (black-filled arrows). (B) Detail of the pollen wall showing gold labelling in both the exine (empty arrows) and the material adhered to the exine (white-filled arrows). (C) Negative control section where anti-actin antibody was omitted. Abbreviations: Cy, cytoplasm; Ex, exine In, intine; V, vesicle. Bars: $1 \mu \mathrm{m}$.

demonstrated at the cellular level for several allergens of birch, grasses and olive pollens (Grote et al., 1993; Vrtala et al., 1993; Alché et al., 2004). In the case of timothy grass, profilin was released rapidly and in large amounts from the hydrated pollen, whereas the same allergen was retained in the hydrated pollen grain of birch (Vrtala et al., 1993). The leakage of allergenic proteins to the medium has been proposed to take place through microchannels from the entire surface of the pollen grain, whereas longer exposure times have been proposed to give rise to a massive leaching of the allergen out of the germination pores (Howlett et al., 1973; Grote et al., 1993). In the olive pollen, the presence of an intense labelling corresponding to profilin in the culture medium and the pollen exine indicates that olive pollen profilin is also massively released into aqueous media upon pollen hydration. Intense fluorescence localized in a ring-like distribution surrounding the effective apertures may represent a clear evidence of this substantial release of profilin. The mechanisms underlying this discharge may involve or be dependent on some kind of physiological transport or cell activity as non-germinating pollen grains display a nearly null level of exine labelling. On the other hand, a ring-like labelling only occurs around the emergence place of the pollen tube, and not in the other two apertural regions. This huge leak of allergens, which in olive affects at least Ole e 1 and Ole e 2 allergens (Carnés et al., 2002; Alché et al., 2004 and the present work), makes them readily available to the immune system and characterizes them as potent allergens.

Regarding actin visualization, although the use of conventional chemical fixation procedures has been described to induce disruptive rearrangements of actin, which notably includes microfilaments (He \& Wetzstein, 1995; Doris \& Steer, 1996), a general picture of actin organization in the olive pollen tube can be drawn from the present work, after comparison with the current overview of actin organization (Ren \& Xiang, 2007). The actin labelling detected in the olive pollen tube likely represents areas of high density of microfilaments, and/or large accumulations of free/bound actin monomers, which are recognized by the antibody. The fluorescence that accumulated in both the pollen tube apical zone and the proximal regions of the pollen tube may indicate the presence of regions involved in very high actin metabolism. Both regions also coincide with areas of high concentration of profilin in the olive pollen. Mittermann et al. (1995) also have described a more intense staining of profilin in the tip of growing pollen tubes of tobacco. In other tip-growing cell types like growing root hairs, the profilins are specifically localized to the tip region (Braun et al., 1999; Baluska et al., 2000). The colocalization of Ole e 2 and actin in the effective pollen aperture and the apical region of the pollen tube can be interpreted as an evidence of a massive dissociation of the actin-profilin complexes, as has been previously suggested (Grote et al., 

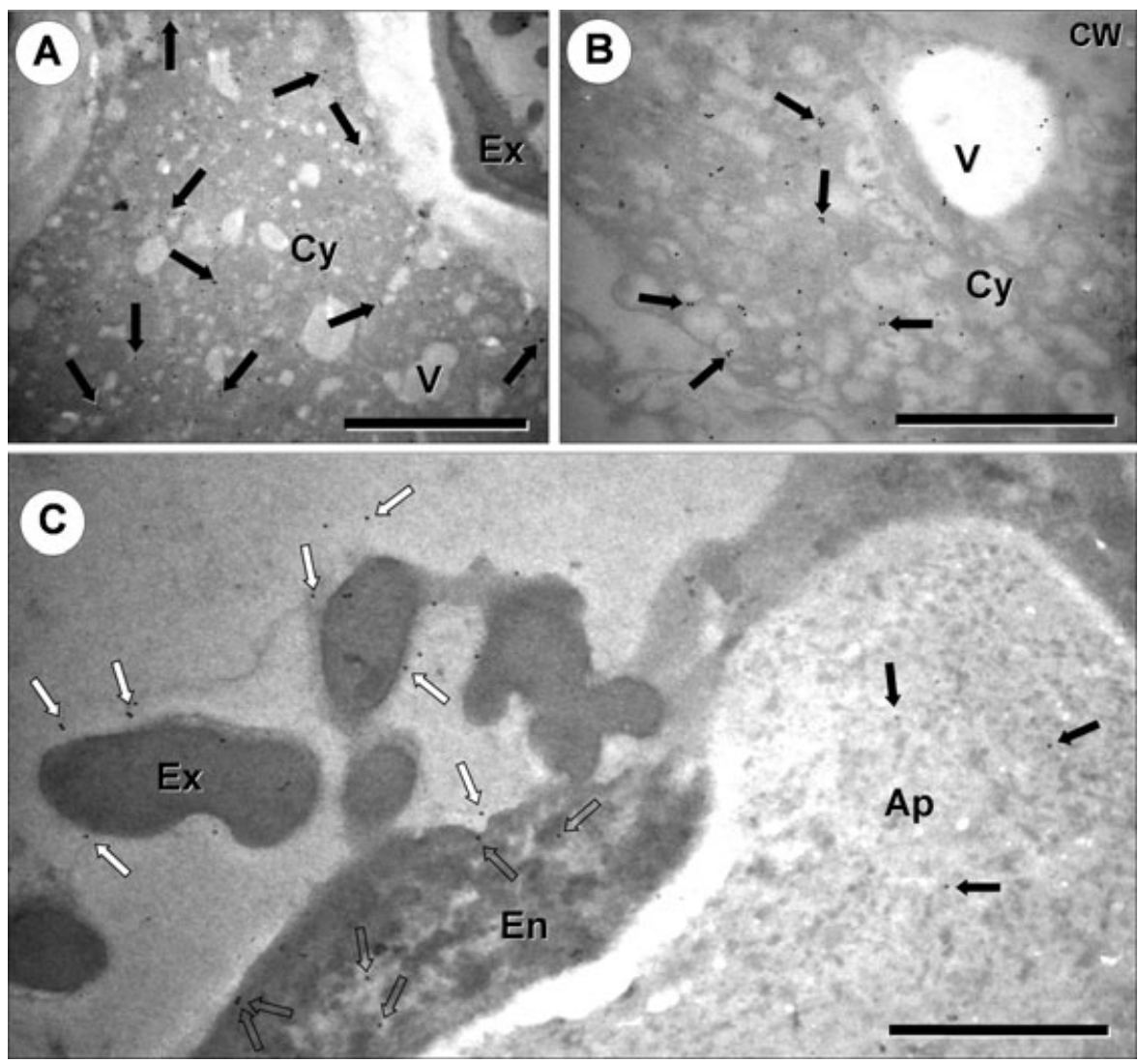

Fig. 6. TEM immunolocalization of profilin on ultra-thin sections of germinating pollen grains. (A) Vegetative cell cytoplasm and proximal pollen tube cytoplasm. Gold labelling (black-filled arrows) is extended within the pollen tube cytoplasm. (B) Detail of the pollen tube cytoplasm. Gold particles decorate uniformly the cytoplasm and are absent from the vacuoles and vesicles. (C) Aperture region showing intense gold labelling (black-filled arrows). Gold particles are numerous in the endexine aperture (empty arrows). The material adhered to the exine, also intensely labelled by gold particles, is shown by the white-filled arrows. Abbreviations: Ap, aperture; CW, cell wall; Cy, cytoplasm; En, endexine; Ex, exine; V, vesicle. Bars: $1 \mu \mathrm{m}$.

1993), or a mobilization of the stored monomer-actin, and therefore, an initiation of polymerization of the actin filaments in these areas. This remarkable activity may begin to occur in the three apertural regions of the pollen grain to finally focus on the 'effective' pollen aperture and the pollen tube itself, particularly in these anchor regions corresponding to both ends of the pollen tube. These two ends could be considered as major places for the formation, dynamics and cell control over the actin cytoskeleton, enabling both the polarized outgrowth of the pollen tube and the presence of the 'reverse fountain' cytoplasmic streaming (Vidali \& Hepler, 2001; Cárdenas et al., 2005), which we have widely observed in olive pollen tubes (unpublished results). The use of enhanced procedures for the fixation of pollen samples and visualization of actin and profilin, as described by Lovy-Wheeler et al., (2005), will undoubtedly improve our view of the olive pollen cytoskeleton, telling us whether structures like the cortical fringe of actin present in the tube apex in Lilium (Vidali \& Hepler, 2001; Lovy-Wheeler et al., 2005) are also present in olive.

The use of specific antibodies to each one of the profilin isoforms, all of them recognized by the currently used anti-serum, will also provide further information regarding a putative differential localization of profilin isoforms, as described in different plant sources (von Witsch et al., 1998; Kandasamy et al., 2002; Ren \& Xiang, 2007).

The ultrastructural localization of profilin in the pollen grain and pollen tube from different plant species has been investigated using immunocy tochemical analyses (Grote et al., 1993, 1995; Hess et al., 1995; Fischer et al., 1996; Vidali \& Hepler, 1997; Kandasamy, 2002). With a few exceptions (i.e. Fischer et al. (1996) localized Phl p 4 in the amyloplasts of timothy grass pollen), most authors localized profilin in the cytoplasm and exine of the pollen grain and the cytoplasm of the pollen tube. In the olive pollen, profilin is also consistently located like a soluble protein, uniformly distributed in the cytoplasm of both the pollen grain and the pollen tube, lacking any preferential localization or binding to the organelles, structures or compartments. Only the widespread presence of gold labelling associated with the exine, the material adhered to the exine and the aperture endexine may be considered distinctive, representing evidence of the massive release of allergen also observed by immunofluorescence. 


\section{Acknowledgements}

This work was funded by the Spanish Ministry for Education and Research (MEC) project BFU2004-00601/BFI and by the Consejería de Innovación, Ciencia y Empresa, Junta de Andalucia (JA), project P06-AGR-01791. The authors want to thank C. Martínez-Sierra for the technical assistance.

\section{References}

Alché, J.D., Castro, A.J., Olmedilla, A., Fernández, M.C., Rodríguez, R., Villalba, M. \& Rodríguez-García, M.I. (1999) The major olive pollen allergen (Ole e I) shows both gametophytic and sporophytic expression during anther development, and its synthesis and storage takes place in the RER. J. Cell Sci. 112(15), 2501-2509.

Alché, J.D., M'rani-Alaoui, M., Castro, A.J. \& Rodríguez-García, M.I. (2004) Ole e 1, the major allergen from olive (Olea europaea L.) pollen, is newly synthesized and released to the culture medium during in vitro germination. Plant Cell Physiol. 45(8), 1149-1157.

Baluska, F., Samaj, J., Mathur, J., Braun, M., Jasper, F., Chua, N.H., Barlow, P.W. \& Volkmann, D. (2000) Root hair formation: F-actin-dependent tip growth is initiated by local assembly of profilin-supported F-actin meshworks accumulated within expansin-enriched bulges. Dev. Biol. 227, 618-632.

Bedinger, P.A. \& Edgerton, M.D. (1989) Developmental staging of maize microspores reveals a transition in developing microspore protein. Plant Physiol. 92, 474-479.

Bedinger, P.A., Hardeman, K.L. \& Loukides, C.A. (1994) Travelling in style: the cell biology of pollen. Trends Cell Biol. 4, 132-138.

Bradford, M.M. (1976) A rapid and sensitive method for the quantitation of microgram quantities of protein utilizing the principle of protein-dye binding. Anal. Biochem. 7(72), 248-254.

Braun, M., Baluška, F., von Witsch, M. \& Menzel, D. (1999) Redistribution of actin, profilin and phosphatidylinositol-4,5-bisphosphate in growing and maturing root hairs. Planta 209, 435-443.

Cao, L.G., Babcock, G.G., Rubenstein, P.A. \& Wang, Y.L. (1992) Effects of profilin and profilactin on actin structure and function in living cells. J. Cell Biol. 117(5), 1023-1029.

Cárdenas, L., Lovy-Wheeler, A., Wilsen, K.L. \& Hepler P.K. (2005) Actin polymerization promotes the reversal of streaming in the apex of pollen tubes. Cell Motil. Cytoskel. 61(2), 112-127.

Carlier, M.F. \& Pantaloni, D. (1994) Actin assembly in response to extracellular signals: role of capping proteins, thymosin beta 4 and profilin. Semin. Cell Biol. 5, 183-191.

Carnés, J., Fernández-Caldas, E., Boluda, L., Casanovas, M., Sastre, J., Lluch Bernal, M. \& Blanca, M. (2002) Rapid release of Ole e 1 from olive pollen using different solvents. Allergy 57, 798-804.

Chen, C.Y., Wong, E.I., Vidali, L., Estavillo, A., Hepler, P.K., Wu, H.M. \& Cheung, A.Y. (2002) The regulation of actin organization by actindepolymerizing factor in elongating pollen tubes. Plant Cell 14(9), 2175-2190.

Deeks, M.J., Hussey, P.J. \& Davies, B. (2002) Formins: intermediates in signal cascades that affect cytoskeletal reorganization. Trends Plant Sci. 7, 492-498.

Doris, F.P. \& Steer, M.W. (1996) Effects of fixatives and permeabilisation buffers on pollen tubes: implications for localisation of actin microphilaments using phalloidin staining. Protoplasma 195, 25-36. dos Remedios, C.G., Chhabra, D., Kekic, M., Dedova, I.V., Tsubakihara, M., Berry, D.A.\& Nosworthy, N.J. (2003) Actin binding proteins: regulation of cytoskeletal microfilaments. Physiol. Rev. 83, 433-473.

Fedorov, A.A., Ball, T., Mahoney, N.M., Valenta, R. \& Almo, S.C. (1997) The molecular basis for allergen cross-reactivity: crystal structure and IgE-epitope mapping of birch pollen profilin. Structure 5, 33-45.

Fedorov, A.A., Magnus, K.A., Graupe, M.H., Lattman, E.E., Pollard, T.D. \& Almo, S.C. (1994) X-ray structures of isoforms of the actin-binding protein profilin that differ in their affinity for phosphatidylinositol phosphates. Proc. Natl. Acad. Sci. U.S.A. 91, 8636-8640.

Fischer, S., Grote, M., Fahlbusch, B., Muller, W.D., Kraft, D. \& Valenta, R. (1996) Characterization of Phl p 4, a major timothy grass (Phleum pratense) pollen allergen. J. Allergy Clin. Immunol. 98(1), 189198.

Friml, J., Benková, E., Mayer, U, Palme, K. \& Muster, G. (2003) Automated whole mount localisation techniques for plant seedlings. Plant J. 34, $115-124$

Geitman, A. \& Emons A.M.C. (2000) The cytoskeleton in plant and fungal cell tip growth. J. Micros. 198, 218-245.

Gibbon, B.C., Ren, H. \& Staiger, C.J. (1997) Characterization of maize (Zea mays) pollen profilin function in vitro and in live cells. Biochem. J. 327, 909-915.

Gibbon, B.C.\& Staiger, C.J. (2000) Profilin. Actin: A Dynamic Framework for Multiple Plant Cell Functions (ed. by C.J. Staiger, F. Baluska, D. Volkmann and P. Barlow), pp. 45-65. Kluwer Academic Publishers, Dordrecht, The Netherlands.

Gibbon, B.C., Zonia, L.E., Kovar, D.R., Hussey, P.J. \& Staiger, C.J. (1998) Pollen profilin function depends on interaction with proline-rich motifs. Plant Cell 10, 981-994. [Correction: Plant Cell 11, 1603].

Goldschmidt-Clermont, P.J. \& Janmey, P.A. (1991) Profilin, a weak cap for actin and ras. Cell 66, 419-421.

Grote, M., Swoboda, I., Meagher, R.B. \& Valenta, R. (1995) Localization of profilin- and actin-like immunoreactivity in in vitro-germinated tobacco pollen tubes by electron microscopy after special water-free fixation techniques. Sex. Plant Reprod. 8, 180-186.

Grote, M., Vrtala, S. \& Valenta, R. (1993) Monitoring of two allergens, Bet v I and profilin, in dry and rehydrated birch pollen by immunogold electron microscopy and immunoblotting. J. Histochem. Cytochem. 41(5), 745-750.

Haugwitz, M., Noegel, A.A., Karakesisoglou, J. \& Schleicher, M. (1994) Dictyostelium amoeba that lack G-actin-sequestering profilins show defects in F-actin content, cytokinesis, and development. Cell 79, 303314.

He, Y. \& Wetzstein, H. (1995) Fixation induces differential tip morphology and immunolocalization of the cytoskeleton in pollen tubes. Physiol. Plant. 93, 757-763.

Hess, M.W., Mittermann, I., Luschnig, C. \& Valenta, R. (1995) Immunocytochemical localisation of actin and profilin in the generative cell of angiosperm pollen: TEM studies on high-pressure frozen and freeze-substituted Ledebouria socialis Roth (Hyacinthaceae). Histochem. Cell Biol. 104(6), 443-451.

Holzinger, A., Mittermann, I., Laffer, S., Valenta, R. \& Meindl, U. (1997) Microinjection of profilins from different sources into the green alga Micrasterias causes transient inhibition of cell growth. Protoplasma 199, 124-134.

Howlett, B.J., Knox, R.B. \& Heslop-Harrison, J. (1973) Pollen wall proteins: release of the allergen antigen $\mathrm{E}$ from intine and exine sites in the pollen grains of ragweed and Cosmos. J. Cell Sci. 13, 603. 
Huang, S., Blanchoin, L., Kovar, D.R. \& Staiger C.J. (2003) Arabidopsis capping protein (AtCP) is a heterodimer that regulates assembly at the barbed ends of actin filaments. J. Biol. Chem. 278, 44832-44842.

Kandasamy, M.K., McKinney, E.C. \& Meagher, R.B. (2002) Plant profilin isovariants are distinctly regulated in vegetative and reproductive tissues. Cell Motil. Cytoskeleton. 52(1), 22-32.

Laemmli, U.K. (1970) Cleavage of structural proteins during the assembly of the head of bacteriophage T4. Nature 227, 680-685.

Ledesma, A., Rodriguez, R., Villalba, M. (1998) Olive-pollen profilin. Molecular and immunologic properties. Allergy 53(5), 520-526.

Lee, S.S., Karakesisoglou, I., Noegel, A.A., Rieger, D. \& Schleicher, M. (2000) Dissection of functional domains by expression of point-mutated profilins in Dictyostelium mutants. Eur. J. Cell Biol. 79, 92-103.

Lovy-Wheeler, A., Wilsen, K.L., Baskin, T.I. \& Hepler, P.K. (2005) Enhanced fixation reveals the apical cortical fringe of actin filaments as a consistent feature of the pollen tube. Planta 221(1), 95-104.

Machesky, L.M. \& Pollard, T.D. (1993) Profilin as a potential mediator of membrane-cytoskeleton communication. Trends Cell Biol. 3, 381-385.

Martínez, A., Asturias, J. A., Monteseirín, J., Moreno, V., García-Cubillana A., Hernández M., de la Calle A., Sánchez-Hernández C., Pérez-Formoso, J. L. \& Conde J. (2002) The allergenic relevance of profilin (Ole e 2) from Olea europaea pollen. Allergy 57(Suppl. 71), 17-23.

Mascharenhas, J.P. (1993) Molecular mechanisms of pollen tube growth and differentiation. Plant Cell 5, 1303-1314.

Mittermann, I., Swoboda, I., Pierson, E., Eller, N., Kraft, D., Valenta, R. \& Heberle-Bors, E. (1995) Molecular cloning and characterization of profilin from tobacco (Nicotiana tabacum): increased profilin expression during pollen maturation. Plant Mol. Biol. 27(1), 137-146.

M'rani-Alaoui, M. (2000) Estudio a nivel celular de la germinación del polen, emisión y elongación del tubo polínico en el olivo (Olea europaea L.). Ph. D. Thesis, University of Granada, Spain.

Pantaloni, D. \& Carlier, M.F. (1993) How profilin promotes actin filament assembly in the presence of thymosin beta4. Cell 75, 1007-1014.

Perelroizen, I., Didry, D., Christensen, H., Chua, N.-H. \& Carlier, M.-F. (1996) Role of nucleotide exchange and hydrolysis in the function of profilin in actin assembly. J. Biol. Chem. 271, 12302-12309.

Ren, H. \& Xiang, Y. (2007) The function of actin-binding proteins in pollen tube growth. Protoplasma 230(3-4), 171-182.

Rodríguez, R., Villalba, M., Batanero, E., González, E.M., Monsalve R.I., Huecas, S., Tejera, M.L. \& Ledesma A. (2002) Allergenic diversity of the olive pollen. Allergy 57(Suppl. 71), 6-16.

Schlüter, K., Jockusch, B.M. \& Rothkegel, M. (1997) Profilins as regulators of actin dynamics. Biochim. Biophys. Acta. 1359, 97-109.

Schutt, C.E., Myslik, J.C., Rozycki, M.D., Goonesekere, N.C. \& Lindberg, U. (1993) The structure of crystalline profilin-beta-actin. Nature 365, 810-816.

Staiger, CJ. 2000. Signaling to the actin cytoskeleton in plants. Ann. Rev. Plant Physiol. Plant Mol. Biol. 51, 257-288.
Staiger, C.J. \& Blanchoin, L. (2006) Actin dynamics: old friends with new stories. Curr. Opin. Plant Biol. 9, 554-562.

Staiger, C.J., Gibbon, B.C., Kovar, D.R. \& Zonia, L.E. (1997) Profilin and actin depolymerizing factor: modulators of actin organization in plants. Trends Plant Sci. 2, 275-281.

Staiger, C.J., Yuan, M., Valenta, R., Shaw, P.J., Warn, R.M. \& Lloyd, C.W. (1994) Microinjected profilin affects cytoplasmic streaming in plant cells by rapidly depolymerizing actin microfilaments. Curr. Biol. 4, 215-219.

Szechynska-Hebda, M., Wedzony, M., Dubas, E., Kieft, H. \& Van Lammeren, A. (2006) Visualisation of microtubules and actin filaments in fixed BY-2 suspension cells using an optimised whole mount immunolabelling protocol. Plant Cell Reports. 25(8), 758766.

Taylor, L.P. \& Hepler, PK (1997) Pollen germination and tube growth. Ann. Rev. Plant Physiol. Plant Mol. Biol. 48, 461-491.

Theriot, J.A. \& Mitchison, T.J. (1993) The three faces of profilin. Cell 75, 835-838.

Valenta, R., Duchene, M., Pettenburger, K., Sillaber, C., Valent, P., Bettelheim, P., Breitenbach, M., Rumpold, H., Kraft, D. \& Scheiner, O. (1991) Identification of profilin as a novel pollen allergen: IgE autoreactivity in sensitized individuals. Science 253(5019), 557560.

Valenta, R., Ferreira, F., Grote, M., Swoboda, I., Vrtala, S., Duchêne, M., Deviller, P., Meagher, R.B., McKinney, E., Heberle-Bors, E., Kraft D. \& Scheiner, O. (1993) Identification of profilin as an actin binding protein in higher plants. J. Biol. Chem. 268, 22777-22781.

Valster, A.H., Pierson, E.S., Valenta, R., Hepler, P.K. \& Emons, A.M.C. (1997) Probing the plant actin cytoskeleton during cytokinesis and interphase by profilin microinjection. Plant Cell. 9, 1815-1824.

Valster, A.H., Vidali, L. \& Hepler, P.K. (2003) Nuclear localization of profilin during the cell cycle in Tradescantia virginiana stamen hair cells. Protoplasma 222(1-2), 85-95.

Vidali, L. \& Hepler, P.K. (1997) Characterization and localization of profilin in pollen grains and tubes of Lilium longiflorum. Cell Motil. Cytoskel. 36(4), 323-338.

Vidali, L. \& Hepler, P.K. (2001) Actin and pollen tube growth. Protoplasma 215(1-4), 64-76.

Vinson, V.K., Archer, S.J., Lattman, E.E., Pollard, T.D. \& Torchia, D.A. (1993) Three-dimensional solution structure of Acanthamoeba profilinI. J. Cell Biol. 122, 1277-1283.

von Witsch, M., Baluska, F., Staiger, C.J. \& Volkmann, D. (1998) Profilin is associated with the plasma membrane in microspores and pollen. Eur. J. Cell Biol. 77(4), 303-312.

Vrtala, S., Grote, M., Duchene, M., van Ree, R., Kraft, D., Scheiner, O. \& Valenta, R. (1993) Properties of tree and grass pollen allergens: reinvestigation of the linkage between solubility and allergenicity. Int. Arch. Allergy Immunol. 102(2), 160-169. 